\title{
Evaluation of single whole inclusion serum test for IgG antibody to Chlamydia trachomatis in asymptomatic women
}

\author{
MICHAEL P MEYER* $\ddagger$ AND ANTONIO J AMORTEGUI* $\ddagger$ \\ From the *Department of Pathology, Magee-Womens Hospital, the †University of Pittsburgh School of \\ Medicine, and the $\ddagger$ Department of Medical Technology, School of Health Related Professions, University of \\ Pittsburgh, Pittsburgh, Pennsylvania, United States of America
}

SUMMARY IgG antibody titres against Chlamydia trachomatis were measured using a whole inclusion assay (Electro-Nucleonics Laboratories, Bethesda, Maryland, USA) in single serum samples of patients who presented for termination of pregnancy with evidence of infection with this organism (case group) and of 30 women with no evidence of infection (control group). Case and control patients were matched for age, race, marital status, history of sexually transmitted diseases, number of lifetime sexual partners, and whether they had had a new sexual partner in the preceding month. Fifty eight of $60(97 \%)$ serum samples tested had chlamydial antibodies present at a titre of $1 / 8$ or more. There was no significant difference between the geometric mean titres of the 30 case patients and the 28 controls with chlamydial antibodies (1/161.3 and $1 / 77.4$ respectively). Significantly more case patients than controls, however, had a titre of $1 / 128$ or more $(p<0.01)$. The sensitivity, specificity, and positive and negative predictive values of a single serum antibody titre of $1 / 128$ or more as an indicator of recent infection compared with isolation of the organism in cycloheximide treated McCoy cells or antigen detection by Chlamydiazyme (Abbot Laboratories; North Chicago, Illinois, USA), or both, were each $67 \%$. The value of the antibody assay seems to be questionable as high levels of antibodies failed to correlate with isolation or antigen detection results, or both, in our population.

\section{Introduction}

Evidence implicating Chlamydia trachomatis as the agent responsible for a large number of inflammatory processes affecting neonates, infants, and adults of both sexes has accumulated in published reports. At present, the most accepted means of diagnosing infections caused by $C$ trachomatis is the isolation of the organism in cycloheximide treated McCoy cells, though several methods independent of culture have recently been developed. ${ }^{12}$ As isolation is technically difficult, expensive, and not readily available, some workers have explored the use of serological methods to detect infections with this Gram negative, obligate,

Address for reprints: Mr Michael P Meyer, Department of Pathology, Magee-Womens Hospital, Forbes and Halket Street, Pittsburgh, Pennsylvania 15213, USA

Accepted for publication 26 May 1986 intracellular bacterium. Though the microimmunofluorescence test developed by Wang is generally regarded as the most reliable serological test, ${ }^{3}$ its complexicity even when simplified has prohibited its use in most clinical laboratories. Indirect immunofluorescence serum antibody assays using McCoy cells infected with lymphogranuloma venereum type 2 as the antigen source have therefore been advocated by some authors instead of microimmunofluorescence. ${ }^{46}$ A commercial antibody kit using this principle has recently become available, and we report here an evaluation of this test in mainly asymptomatic women.

Patients, materials, and methods

STUDY POPULATION AND COLLECTION OF SPECIMENS After obtaining signed informed consent, we took cervical material for culture (using two cotton tipped 
swabs on plastic shafts) from 425 patients attending the abortion clinic of Women's Health Services (Pittsburgh, Pennsylvania, United States of America) between August and November 1983, before termination of pregnancy. The first swab was placed in $1.5 \mathrm{ml}$ chlamydial transport medium consisting of $0.1 \mathrm{~mol} / 1$ sucrose in $0.02 \mathrm{~mol} / \mathrm{l}$ phosphate buffer $(\mathrm{pH} \mathrm{7.2)}$ and supplemented with $10 \%$ fetal bovine serum (prescreened for antichlamydial properties), $0 \cdot 125 \mathrm{mg} / \mathrm{ml}$ vancomycin, $0.05 \mathrm{mg} / \mathrm{ml}$ streptomycin, 25 units $/ \mathrm{ml}$ nystatin, and $0.01 \mathrm{mg} / \mathrm{ml}$ amphotericin $B$. The second swab was placed in a special transport buffer and assayed by an enzyme immunoassay for antigens to $C$ trachomatis, (Chlamydiazyme; Abbott Laboratories, North Chicago, Illinois, USA). ${ }^{1}$ Serum was separated from a $10 \mathrm{ml}$ blood sample and stored at $-20^{\circ} \mathrm{C}$.

Demographic and sexual history data were obtained from each patient using a standardised questionnaire. All swabs were kept on wet ice or refrigerated and transported to the laboratory within 18 hours of collection. The two cervical swab specimens obtained from all 425 women were used to isolate $C$ trachomatis in cycloheximide treated $\mathrm{McC}$ oy cells and for the antigen detection assay as described below. Serum from 30 case patients with and 30 control patients without evidence of chlamydial infection was tested for chlamydial IgG antibodies. Evidence of chlamydial infection was defined as a positive cervical culture or positive Chlamydiazyme result, or both, regardless of the presence or absence of genital tract symptoms. C trachomatis was isolated from cervical specimens from $24 / 30(80 \%)$ case patients. The remaining six

TABLE I Matching of women infected with Chlamydia trachomatis (cases) and non-infected controls

\begin{tabular}{lcc}
\hline Variables & $\begin{array}{l}\text { Cases } \\
(n=30)\end{array}$ & $\begin{array}{l}\text { Controls } \\
(n=30)\end{array}$ \\
\hline Mean age (years) & $21 \cdot 6$ & $23 \cdot 1$ \\
Martial status: & 23 & 25 \\
$\quad$ Single & 25 & 2 \\
$\quad$ Married & 4 & 3 \\
$\quad$ Divorced & 3 & \\
Race: & 25 & 25 \\
$\quad$ White & 5 & 5 \\
$\quad$ Black & & \\
Previous sexually transmitted diseases: & 1 & 1 \\
Yes & 29 & 29 \\
$\quad$ No & $5 \cdot 4$ & $4 \cdot 4$ \\
Mean No of lifetime sexual partners & & \\
New sexual partners in preceding month: & 3 & 2 \\
Yes & 27 & 28 \\
$\quad$ No & & \\
Genital symptoms present: & 6 & 0 \\
Yes & 24 & 30 \\
$\quad$ No & & \\
\hline
\end{tabular}

case patients from whom the organism was not isolated had a positive cervical Chlamydiazyme test result. Two of these six patients had genital tract symptoms at the time of specimen collection. None of the control patients had genital tract symptoms at the time of sampling. The control patients were matched with the case patients in terms of age, race, marital status, history of sexually transmitted disease, number of lifetime sexual partners, and whether they had had a new sexual partner in the preceding month (table I).

\section{CHLAMYDIAL IDENTIFICATION TESTS}

Of the 425 specimens received for $C$ trachomatis isolation, 200 were kept at $40^{\circ} \mathrm{C}$ and processed within 24 hours of collection. The remaining 225 specimens were stored at $-80^{\circ} \mathrm{C}$ and processed within 21 days. Isolation of $C$ trachomatis in cycloheximide treated McCoy cells was undertaken as described previously. ${ }^{1}$ In short, specimens were inoculated on to McCoy cell monolayers on $13 \mathrm{~mm}$ diameter coverslips in $3.7 \mathrm{ml}$ (1 dram) shell vials and centrifuged at $2800 \times g$ for 60 minutes at $35^{\circ} \mathrm{C}$. The inoculum was then removed and replaced with medium containing $1 \mathrm{mg} / 1$ cycloheximide. After incubation for 65 to 90 hours, one monolayer was stained by Giemsa and one by immunofluorescent monoclonal antibody methods for $C$ trachomatis inclusions. ${ }^{78}$ The remaining monolayers were subcultured by removing the cycloheximide medium, adding several sterile glass beads to each vial, and vortexing. The disrupted cells were resuspended in $1 \mathrm{ml}$ medium and processed as above. Cultures were considered to be positive on primary isolation or subculturing, or both, if one or more inclusions were observed after either staining procedure. Detection of chlamydial antigens by Chlamydiazyme was performed as described previously. ${ }^{1}$

\section{SEROLOGICAL PROCEDURE}

The serum samples were stored at $-20^{\circ} \mathrm{C}$ and tested for specific IgG antibodies to $C$ trachomatis using the test kit of Electro-Nucleonics Laboratories (Bethesda, Maryland, USA) according to the manufacturer's instructions. In short, twofold serial dilutions of each serum sample were made in phosphate buffered saline (PBS) in microtitre plates. Then $10 \mu l$ of each dilution from $1 / 8$ to $1 / 1024$ was placed in one well on a glass slide containing previously fixed infected McCoy cells as the source of antigen. The slides were incubated for 30 minutes in a moist chamber at $37^{\circ} \mathrm{C}$, rinsed in PBS several times, placed in PBS for 15 minutes, removed, and air dried at room temperature. Then $10 \mu \mathrm{l}$ of goat anti-human fluorescein conjugated IgG supplied in the kit was placed in each well and the slides were incubated and rinsed in PBS as above. After being air dried, the slides were mounted with buffered glycerol (pH 8.0) and observed for specific fluorescence using a Leitz epifluorescent microscope. 
Positive and negative controls supplied in the kit were run with each batch of specimens as well as several low and high titred serum samples previously tested by microimmunofluorescence at the University of Washington (Seattle, Washington, USA). The appropriate matched control and case serum samples were tested in the same batch of specimens. Serum samples were coded, and the immunofluorescence results were read independently by one of the authors (MPM) who did not know the isolation and Chlamydiazyme results or whether serum samples were from case or control patients. The endpoint titres were recorded as the last dilution at which specific fluorescence was observed in the infected McCoy cells. All specimens were stored at $4^{\circ} \mathrm{C}$ and assayed again within 48 hours. The retest results were generally within one dilution of the original results, and the original titres are therefore presented.

The $\chi^{2}$ test and Student's $t$ test were used for the statistical analysis.

\section{Results}

All 30 case patients and $27 / 30(90 \%)$ control subjects had chlamydial antibodies at a titre of $1 / 16$ or more. Serum from one control patient had a titre of $1 / 8$. Thus $28 / 30(93.3 \%)$ control women had IgG antibodies to $C$ trachomatis. The geometric mean titres for the 30 case patients and the 28 control women with chlamydial antibodies were $1 / 161 \cdot 3$ and $1 / 77 \cdot 4$ respectively, which was not a significant difference (Student's $t$ test).

An antibody titre of $1 / 128$ or more was interpreted by Electro-Nucleonics as usually indicating recent or current infection. Table II correlates the antibody titres with identification of the organism in cycloheximide treated McCoy cells or Chlamydiazyme, or both, using the $1 / 128$ titre as the cut off value for current infection. Serum samples from more $(67 \%$, $20 / 30)$ case patients than controls $(33 \%, 10 / 30)$ had a

TABLE II Comparison of serum chlamydial antibody titres* in infected $\dagger$ (cases) and non-infected (controls) patients (figures are numbers (\%) of patients)

\begin{tabular}{llll}
\hline $\begin{array}{l}\text { Serum } \\
\text { titre* }\end{array}$ & $\begin{array}{l}\text { Cases } \\
(n=30)\end{array}$ & $\begin{array}{l}\text { Controls } \\
(n=30)\end{array}$ & Total \\
\hline$<1 / 128$ & $10(33)$ & $20(67)$ & 30 \\
$\geq 1 / 128$ & $20(67)$ & $10(33)$ & 30 \\
Total & 30 & 30 & 60 \\
\hline
\end{tabular}

*Serum chlamydial IgG antibody titres were measured using the kit of Electro-Nucleonics, Bethesda, Maryland, USA.

$\dagger$ Infected patients defined as those from whom a positive chlamydial cervical isolation or Chlamydiazmye results, or both, were obtained. titre of $1 / 128$ or more $\left(x^{2} p<0.01\right)$. The sensitivity, specificity, and positive and negative predictive values of the antibody test using the cut off value compared with isolation or Chlamydiazyme testing, or both, were each $67 \%$.

Using only the 24 case patients yielding $C$ trachomatis and their 24 appropriately matched controls, the sensitivity, specificity, and positive and negative predictive values of the $1 / 128$ titre cut off were $70 \%, 63 \%, 65 \%$, and $68 \%$ respectively. When only the 24 asymptomatic case patients and their matched controls were considered, no significant difference between the two groups was found, as serum from $15 / 24(63 \%)$ of case patients and $10 / 24(42 \%)$ controls had titres of $1 / 128$ or more.

\section{Discussion}

In this limited case controlled study using the ElectroNucleonics test for serum IgG antibodies against $C$ trachomatis, most of the patients studied had apparently been exposed to $C$ trachomatis previously, as $58 / 60(97 \%)$ had titres of $1 / 8$ or more. Serum samples containing specific antibody at a titre of $1 / 128$ or more were taken from more case patients than controls, though no signficiant difference between the geometric mean titres was found. In this setting, therefore, a single antibody titre estimation has little value on an individual basis because of the low sensitivity $(67 \%)$ using the interpretation offered by the manufacturer. The specificity and positive and negative predictive values of the antibody assay were also each $67 \%$, and a titre of $1 / 128$ or more was therefore difficult to relate to isolation or antigen detection results. We cannot, however, rule out the possibility that $C$ trachomatis infection may have occurred at another anatomical site. It is also possible that patients with "false positive" antibody tests (titre $1 / 128$ or more with negative isolation or Chlamydiazyme results) may have eliminated the organism from the cervix naturally before sample collection. Also, isolation of the organism in cycloheximide treated McCoy cells may not be a sensitive enough procedure to detect some asymptomatic infections. As patients from whom $C$ trachomatis antigens were detected by Chlamydiazmye were also included in the case group, however, we are confident that all current infections were found.

The manufacturer's instructions do not specify which serotype of $C$ trachomatis was used to make the substrate slides. It is clear that the serotype antigen could affect the titre results.910 Furthermore, antinuclear antibodies may produce non-specific reac tions in the single antigen test for antibodies to $C$ trachomatis. High levels of antinuclear antibodies present in some serum samples need to be differentiated from the fluorescence due to specific antibodies 
to $C$ trachomatis to avoid false positive interpretations. Autoantibodies may also mask the detection of antibodies to $C$ trachomatis. The manufacturer's directions fail to mention this problem or suggest methods to remove these autoantibodies, such as absorption with uninfected cells. ${ }^{11}$

Reports from Scandinavia have indicated a high rate of pelvic inflammatory disease after termination of pregnancy in women with chlamydial infection. ${ }^{12-16}$ We cannot therefore recommend the use of this antibody test as a replacement for isolation or detection of antigen in patients considered for termination of pregnancy or in women previously infected with $C$ trachomatis. Kordova et al also found that the presence of chlamydial antibodies as detected with Electro-Nucleonics' assay did not correlate with isolation results in patients from Manitoba, Canada, who had symptoms suggestive of genital chlamydial infections. ${ }^{17}$ Other workers have also shown serological testing to be of limited value in diagnosing infections with $C$ trachomatis in patients attending clinics for sexually transmitted diseases and in other populations with a high prevalence of $C$ trachomatis. ${ }^{1018}$ Though a high titre of $1 / 1000$ or more in an indirect fluorescent antibody test may be considered as suggestive of recent infection, the presence of IgM antibody, especially in cases of neonatal chlamydial pneumonia, ${ }^{5}$ or a significant change in titre in paired serum samples would be more important. As shown by the present investigation, serodiagnosis of recent infection is unlikely if based on a single serum sample and at the low cut off IgG titre of $1 / 128$, especially in women. Also, the value of the Electro-Nucleonics test as a screening tool in prenatal, neonatal, infertile, and other patients has not yet been evaluated. Thus the use of this commercial assay for antibodies to $C$ trachomatis cannot be advocated as a routine diagnostic test for ocular or genital chlamydial infections. Serological assays such as the one studied here remain tools for seroepidemiological investigations.

We thank Connie Zatezalo for technical help and Diane Marchionda for help in preparation of this manuscript.

\section{References}

1. Amortegui AJ, Meyer MP. Experience with an enzyme immunoassay for the detection of Chlamydia trachomatis from the cervix. Obstet Gynecol 1985;65:523-6.
2. Tam MR, Stamm WE, Handsfield HH, et al. Cultureindependent diagnosis of Chlamydia trachomatis using monoclonal antibodies. $N$ Engl J Med 1984;310:1146-50.

3. Wang SP. A micro-immunofluorescence method. Study of antibody response to TRIC organisms in mice. In: Nichols RL, ed. Trachoma and related disorders caused by chlamydial agents. Amsterdam: Excerpta Medica, 1971:273-8.

4. Richmond SJ, Caul EO. Fluorescent antibody studies in chlamydial infections. J Clin Microbiol 1975;1:345-52.

5. Beem MO, Saxon EM. Respiratory tract colonization and distinctive pneumonia syndrome in infants infected with Chlamydia trachomatis. N Engl J Med 1977;296:306-10.

6. Saikku P, Paavonen J. Single-antigen immunofluorescence test for chlamydial antibodies. J Clin Microbiol 1978;8:119-22.

7. Munday PE, Johnson AP, Thomas BJ. A comparison of the sensitivity of immunofluorescence and Giemsa for staining Chlamydia trachomatis inclusions in cycloheximide-treated McCoy cells. J Clin Microbiol 1980;33:177-9.

8. Stamm WE, Tam M, Koester M. Detection of Chlamydia trachomatis inclusions in McCoy cell cultures with fluoresceinconjugated monoclonal antibodies. J Clin Microbiol 1983;4:666-8.

9. Oriel JD, Ridgway GL. Laboratory diagnosis of $C$ trachomatis. In: Phillips I, ed. Current topics in infection: genital infection by Chlamydia trachomatis. New York: Elsevier Science Publishing Co, 1982;23-36.

10. Schachter J. Chlamydiae. In: Rose NR, Friedman H, eds. Manual of clinical immunology. 2nd ed. Washington DC: American Society for Microbiology, 1980:700-6.

11. Smith TF. Interference of antinuclear antibodies in serologic tests for chlamydial antibodies using LGV-1 infected McCoy cells. In: Mårdh P-A, Holmes KK, Oriel JD, Piot P, Schachter J, eds. Chlamydial infections. New York: Elsevier Biomedical Press, 1982:337-9.

12. Mårdh P-A, Helin I, Bobeck S, Laurin J, Nilsson T. Colonization of pregnant and puerperal women and neonates with Chlamydia trachomatis. British Journal of Venereal Diseases 1980;55:96-100.

13. Moller BR, Ahrons S, Laurin J, Mårdh P-A. Pelvic infection after elective abortion associated with Chlamydia trachomatis. Obstet Gynecol 1982;59:210-3.

14. Osser S, Persson K. Postabortal pelvic infection associated with Chlamydia trachomatis and the influence of humoral immunity. Am J Obstet Gynecol 1984;150:699-703.

15. Qvigstad E, Skaug K, Jerve F, Fulling P, Ulstrup JC. Pelvic inflammatory disease associated with Chlamydia trachomatis infection after therapeutic abortion: a prospective study. British Journal of Venereal Diseases 1983;59:189-92.

16. Qvigstad E, Skaug K, Jerve F, Vik ISS, Ulstrup JC. Therapeutic abortion and Chlamydia trachomatis infection. British Journal of Venereal Diseases 1982;58:182-3.

17. Kordova N, Sekla L, Wenman WM, Stackiv W, Felthan S. New commercial chlamydial antigen in the serology of chlamydial infections in a selected population of the province of Manitoba. Can J Public Health 1982;73:424-6.

18. Schachter J, Cles L, Ray R, Hines PA. Failure of serology in diagnosing chlamydial infections of the female genital tract. $J$ Clin Microbiol 1979;10:647-9. 